\title{
Interpretation of TRIZ Principles in a Service Related Context
}

\author{
Nadhmi Gazem ${ }^{1} \&$ Azizah Abdul Rahman ${ }^{1}$ \\ ${ }^{1}$ Faculty of Computing, Universiti Teknologi Malaysia, 81310, Skudai, Johor, Malaysia \\ Correspondence: Nadhmi Gazem, Faculty of Computing, Universiti Teknologi Malaysia, 81310, Skudai, Johor, \\ Malaysia. Tel: 6-017-242-1838. E-mail: nadhmigazem@gmail.com
}

Received: April 4, $2014 \quad$ Accepted: April 28, $2014 \quad$ Online Published: June 25, 2014
$\begin{array}{ll}\text { doi:10.5539/ass.v10n13p108 } & \text { URL: http://dx.doi.org/10.5539/ass.v10n13p108 }\end{array}$

\begin{abstract}
A systematic innovation method such as the Theory of Inventive Problem Solving (TRIZ) has powerful tools that can be used to solve contradiction problems in technical or non-technical systems. The most common tool used in TRIZ is 40 inventive principles (IPs). The purpose of this paper is to interpret these IPs from a service prospective. The data was collected from many resources found in the literature. A case study was conducted to prove the feasibility of interpretative IPs. The outcome of this study enhanced the usability of the 40 IPs by including new synonyms for some principles, comprehensive descriptions, and providing suggestions and examples for each principle. The interpretative principles focused on a service process used to fulfill customer demands. An Interpretation of TRIZ tool such as the 40 IPs in a service related context improves the understanding of these principles by researchers or service designers.
\end{abstract}

Keywords: TRIZ, inventive principles, service design, service redesign approaches, service context, innovation, business to customer

\section{Introduction}

Even though the Theory of Inventive Problem Solving (TRIZ) was designed to be used in technical areas, current studies are focusing on using TRIZ in non-technology related sectors such as the service sector (Chai et al., 2005; Lin \& Su, 2007; Mann \& Domb, 1999; Regazzoni et al., 2013; Retseptor, 2003; Ruchti \& Livotov, 2001). The fundamental principle behind the TRIZ method is to find contradictions in a system and then eliminate them by using TRIZ tools such as the 40 Interactive Principles (IPs). These tools are important and are frequently used to eliminate contradictions (Cong \& Tong, 2008; Lin \& Su, 2007).

Contradiction analysis in TRIZ uses a contradiction matrix as innovative solutions platform. The matrix includes 39 parameters. The interactions between these parameters in the matrix refer to correspond IPs which guide a problem solver to a solution (Xie et al., 2012). In addition, these parameters help a designer to group principles so that it is easier to find the designer principle. Mann (2007) developed a contradiction matrix for use in a business or management context. Mann's matrix involved 31 business related parameters. However, even though he listed many examples for each IP, the principles were not fully realized.

A problem solver may have difficulties understanding the actual meanings of these IPs in a business related context because the IPs were developed to deal with technical problems. To facilitate using IPs for re-designed services, (Gazem \& Rahman, 2013a; Gazem \& Rahman, 2012) grouped IPs according to five typical Service Redesign Approaches (SRAs) that were developed by (L.Berry \& Lampo, 2000). However, Gazem and Rahman did not explain the meaning of the principles in terms of the service sector. This limitation will be solved in this paper by providing a new structure for elaborating in great detail for each principle. This study is a first attempt at developing a comprehensive description and suggestions (hints) for using each principle in a service related context. Moreover, each hint is accompanied by an example to illustrate in how it has been used by other service providers.

The rest of this paper is divided into six sections. The second section describes the related works in TRIZ inventive principles in service related contexts. In the third section, the methodology was illustrated for interpreting the IPs and how the authors have structured their work. This section also shows the results of interoperation in one table. The fourth section discusses the results of interpreting the 40 IPs and it also indicates several issues found while interpreting the IPs. The feasibility of the results are discussed and demonstrated 
using a case study. Finally, the conclusion, suggestions for future work, and the limitations of this study are presented.

\section{Literature Review}

TRIZ was developed in 1946 by Genrich Altshuller and his colleagues in the former Union of Soviet Socialist Republics (USSR). TRIZ gives the problem solvers different tools. The most commonly used tool for eliminating contradiction problems is 40 IPs (Cong \& Tong, 2008; Lin \& Su, 2007). Eliminating the contradictions from the any system often leads to innovative solutions (Hsia \& Pu, 2013). IPs provide a problem solver with descriptions and examples of how other problem solvers have used a particular principle to overcome the conflict in the system.

The effects of implementing TRIZ in a service related context are promising due to the fact that innovation is critical to revive the service sector (Kuo, Chi, \& Yeh, 2013). Different studies have used several TRIZ IPs tools to help a problem solver find solutions for service system contradictions. Chai, Zhang, and Tan (2005) developed a model for creating new services based on TRIZ and they used the 40 IPs to predict solutions using two case studies. Lin and $\mathrm{Su}$ (2007) reported that 39 parameters formed a contradiction matrix and 40 IPs can be used in the service sector to identify solutions. Kim and Park (2012) recommended adopting a model that links service decision factors and 40 IPs modified for the service industry.

Due to the large number of principles, most TRIZ problem solvers have difficulty managing and remembering each on (Mann, 2002). A few studies have attempted to classify the IPs in order to overcome this issue. For instance, Cong and Tong (2008) classified the 40 IPs using text similarity and meaning similarity into 22 classes to facilitate building an automatic patent classification expert system for TRIZ technical users. Gazem and Rahman (2012) grouped the 40 IPs using service characteristics developed by (L.Berry \& Lampo, 2000).

The interpretation of the TRIZ inventive principles in a service related context varies from one author to another (Cong \& Tong, 2008; Dourson, 2004; Mann \& Domb, 1999). Each author's interpretation depends on imperial experience, their opinions, and using examples from other studies. It is difficult to develop TRIZ principle for the service sector because they have intangible characteristics (Hartman \& Lindgren, 1993; Wolak, Kalafatis, \& Harris, 1998). Table 1 shows how few studies that focused on non-technical sectors defined the 40 IPs.

Table 1. Studies on interpretation of the 40 inventive principles

\begin{tabular}{|c|c|c|}
\hline Authors/ year & Sector & The Output \\
\hline Mann and Domb (1999) & Business & Examples \\
\hline Rantanen and Domb (2002) & Technical and business & $\begin{array}{l}\text { Examples with a some } \\
\text { interpretation for business } \\
\text { in general }\end{array}$ \\
\hline Retseptor, G. (2003). & Quality Management & Examples \\
\hline $\begin{array}{l}\text { J. Zhang, Chai, and Tan } \\
\text { (2003) }\end{array}$ & Service Operations Management. & $\begin{array}{l}\text { Examples with a some } \\
\text { interpretation for business } \\
\text { in general }\end{array}$ \\
\hline Dourson (2004) & Finance & Examples \\
\hline Retseptor (2005) & Marketing, Sales and Advertising & Examples \\
\hline Chai et al. (2005) & New Service Design & Examples \\
\hline $\begin{array}{l}\text { Altshuller, Shulyak, and } \\
\text { Rodman (2005) }\end{array}$ & Technical and business & Examples \\
\hline Mann (2007) & Business and Management & Examples \\
\hline Fox (2008) & Technical and business & Examples \\
\hline Conley (2009) & Business operation & Examples \\
\hline Gazem and Rahman (2013b) & Service redesign & Examples \\
\hline
\end{tabular}

Previous studies have focused on business in order to improve productivity and efficiency. However, interpreting TRIZ for the service sector needs to be more specific. If 40 IPs are interpreted to serve business to business (B2B) 
context, it will be different if 40 IPs are interpreted to serve business to customer (B2C) context. This is because B2B typically focus on relationships between business to other businesses operations, while B2C focus on customers satisfaction and delivering value to them (Q. Zhang, 2013). Thus, this study is oriented to interpret the principles to improve the innovative idea based on $\mathrm{B} 2 \mathrm{C}$ context. When the firm has an innovative idea, it is important to realize who will benefit from this idea and how can those benefits be delivered to customers. In other words, it is not only important to provide innovation but it is also essential to have customers who will benefit from the innovation. Since customer value plays an important role in the innovation process (Gazem \& A.Rahman, 2013), this study focused on interpreting the 40 IPs to enhance the delivery of services to the customer.

\section{Interpretation Structure}

After reviewing previous studies, data and examples were collected data from different secondary resources such as web sites, journal articles, and books to illustrate each principle. Nvivo 10.0 software was used to examine the data, group related examples, and explaining each principle.

In general, each principle in TRIZ consists of two parts. The first part refers to the name of the principle itself, and the second part is a sub-principle that shows how a designer can use the principle to solve a problem. In this study it was discovered that other researcher did not strictly adhered to sub-principle recommendations. This is because those sub-principles were developed for a technical application. Additionally, it is difficult to interpret all the sub-principle and provide business related examples for each one. Therefore, the authors in this have developed new structure for interpreting the 40 IPs.

To facilitate learning and understanding TRIZ principles, each principle must have an introduction, instructions that explain how the problem solver can use this principle, and a demonstration that includes actual examples, as shown in Table 2. The introduction defines the principles in a service sector context. It provides a comprehensive description of the principle, and gives additional information about the principle so that the problem solver can develop a better understanding of the principle. The second section provides instructions (hints). The hints could be seen as the equivalent of the sub-principles in technical TRIZ. The problem solver is not required to adhere to these hints as they can use their experience, knowledge, and own ideas. In general, hints explain how this principle can be used. The third section gives one example for each hint. We found that it is a good idea if we include examples for the hints that demonstrate real life examples and that give a full picture of how the principles were used to solve a service problem.

Table 2. Interpreting 40 inventive principles for performing services

\begin{tabular}{ll}
\hline Principles & Description \\
\hline 1.Segmentation & $\begin{array}{l}\text { The primary goal is to divide the } \\
\text { service process. }\end{array}$
\end{tabular}

Segmentation has contradictory meanings. It can mean dividing a system into parts in order isolate a beneficial or harmful function, or it can mean integrating several components of a system where each component is used to perform a specific task. Segmentation may also change the process that contains the problem in order to create new useful processes for the system.

\section{Hints}

a) Make a service easy to disassemble.

- Some insurance companies have categories for car insurance (first, second, or third party)

b) Break down the services process into small process or increase the degree of fragmentation or segmentation of the service process.

- Supermarkets provide express checkout lanes to expedite the payment process.

c) Target the service to customers based on their needs, ages, buying behaviours, etc.

- Wholesale companies can target customers who are willing to buy in quantity, do without frills, and serve themselves (J. Zhang et al., 2003).

d) Dividing service into several 


\section{Take Off}

(Extraction)

3.Local Quality

(Optimal Resource)
The primary goal here is to separate services.

Low-value service processes may be eliminated or high-value processes may be extracted and used elsewhere in different circumstances. "Extraction" is very similar to "Segmentation" but the difference is that extraction suggests to eliminate the process from the system, while Segmentation offers another way to use the process in the system. Extraction could be actual or virtual (Altshuller et al., 2005). For example, extracting information from a database based using keywords is a virtual extraction, while extracting physical documents from library is an actual extraction.

The primary goal is to customize a service.

Local Quality can refer to customization. It indicates making changes in the service to provide multiple or different features in different environments. Local Quality emphasizes the interaction between location, time, and different features of the service. This principle can be used as lens for changing specific parts of a service that require different conditions or different locations to reach optimal performance. components that can work together or independently.

- Some companies divide the service process to speed of service delivery (e.g., hotels would ask a customer to use the internet to make their reservations.

a) Extract the most wanted or the most unwanted process from the service so that they can work alone.

- Automated Teller Machines (ATM) extract the core functions that essentially perform the banking transactions such as cash withdrawal and funds transfer, and make them performed outside banks.

b) Deliver the service to customer location.

- Post offices in Malaysia in residential areas enable customers to renew car road taxes or driving licenses so that they do not need to travel to official government offices.

c) Change the service operation to self-service.

- Train stations set up automated ticket machines.

d) Outsource a part of a service. (e.g., use another party to perform the most costly processes in a service)

- Online reservation systems (J. Zhang et al., 2003)

a) Change the structure of service from uniform to non-uniform according to the external environment for optimal performance.

- Supermarkets locate goods that are discounted to different places in order that they will be recognized by customers.

b) Customize a service in order to meet customer needs.

- $\quad$ Swimming clubs located swimming pool for adults and another pool for kids.

c) Customize services according to the interaction between customers and the environment, or according to the time of customers demand.

- $\quad$ Some websites give the visitors features to customize the page according to their language or favourite colors. 
d) Make the service capable of accommodating different features.

- Hotels use different features in their websites so that customers can make room reservation and use links to local attractions or taxi services.

e) Use the environment surrounding a service to create a good experience for customers.

- Shopping malls change their internal environments for special occasions such as New Year's celebrations.

4. Asymmetry (Symmetry Change)

5.Merging

(Consolidation)
The primary goal is to differentiate the service.

Asymmetry alters a process so that it is different from standard methods. This principle provides a map that shows designers how to change a service or how to differentiate the service provided for each customer. Implementing asymmetry in a service would bring a new prospective to service performance. For example, telecommunication companies may provide different SIM cards according to user needs, such as special offers for students, youth, or business.

The primary goal is to consolidate services.

Merging means gathering things in order to produce or develop a new method or a new service. It also can be used to combine ideas, needs, and feedback from customers, suppliers, or service providers to produce new services or new delivery methods. It can also be used to think about how existing services can be packaged differently to innovate new services. a) Differentiate a service from the standard to create a custom service or unique experience for customers.

- Banks offer free financial consultation services for clients who make large deposits (J. Zhang et al., 2003).

b) Change the standard interaction between a service provider and the customer.

- Change traditional learning in universities to distance learning.

c) Differentiate customers.

- Using membership cards.

a) Make services work in parallel with other services.

- Grid computing.

b) Package services with other internal or external services.

- Some shops give gifts if the customer buys a particular good, or uses a discount package (buy one get one free).

c) Look to identical services and try operating them together.

- “In shopping malls, cashier counters are usually positioned together to expedite the transaction time" (J. Zhang et al., 2003).

d) Segment customers and provide a service package for them.

- Platinum or gold credit cards: give the customers group of advantages by using 
6.Universality (Multi-functionality)

7.Nested doll ( Nesting)
The primary goal is to use the service for different purposes.

Universality means make something multi-purpose and multi-functional. Service processes can be more effective if it is not acting independently. This principle can be used as lens to find ways of making a service more dynamic and used in different ways or situations. This involves considering how to allow the customer to observe the multiple benefits from the service, or how the services can be used for different purposes to satisfy different customer needs.

The primary goal is to add a new service inside current service.

This principle is about embedding a service inside other services. Nesting service with other services would produce multiple function services. a) Services should offer multiple functions to fulfil various customer needs.

- Internet services that allow customers to perform different processes. For example, a bank website where customers can transfer funds or pay bills.

b) Allow a service to perform different purposes, in different situations, or in different ways.

- In some supermarkets, membership cards can be used for multiple functions such as providing discounts or earning points so customers can use those points later to get a gift or voucher.

c) Eliminate some service processes and substitute them with other processes that can perform same task.

- Instead of having many agent' offices for different tourism companies, one agent office can be used to facilitate ticket sales from different companies.

d) Principles “\#5: Merging” and “\#4: Asymmetry" provide further information about how to create multiple function in a single service.

a) Create a new service inside a current service.

- Messenger applications like Skype has embedded advance Communication and Information Technology (ICT) like Voice Over IP (VOIP) in order to give users another option for making telephone calls (Fox, 2008).

b) Add a new experience for customers by exploiting the environment around a service and add activities to existing services in order to add excitement.

- Air traveling would be a boring 
8. Anti-weight (Counter Balance)

9.Preliminary

Anti-Action (Prior Counteraction)
The primary goal is to mitigate risks.

This principle is can also be named as a "Counterweight". It can be used to avoid heavy loads or expenses. The challenge is to find ways to offset the risk of undesired functions in an exiting service. One option is to move the risk represented by a service to another party. This principle provides a way to control services by mitigating any undesirable effects during service delivery (e.g., angry customer caused by delayed services).

The primary goal here is to prevent potential failure or counteraction before it happens.

Preliminary anti-action ensures that a service will be used without any problems. When the risks or undesirable functions of a service are identified, action can be taken to eliminate, prevent, or reduce potential failures. experience if no extra services like entertainment were incorporated.

c) Nesting a service in a service provided by someone else.

- Samsung nested its Apps market inside the Android operating system to give users more options for downloading applications.

d) Implant technology in a current service.

- Restaurants set a "calling waiter" device in each table.

e) Principle “\#5: Merging” provides further information regarding the creation of multiple and different functionalities.

a) Have more control over services by merging them with the services offered by another service provider.

- Small corporations that sell their products online use e-commerce payment service providers to control the online payment process for them.

b) Shift some service tasks to the customer in order to defray expenses.

- Some companies depend on using customer as a communication medium by word-of-mouth effect for marking their services (J. Zhang et al., 2003).

c) Bundle service with consulting offers.

- Herbalife Company offers free consulting and monitoring in order to ensure customers follow the program.

a) Before negative or harmful effects occur they should be eliminated, prevented or reduced.

- Some companies declare that if their customers are not satisfied with their products or services, they can get their money back (Chai et al., 2005)

b) Have a support plan to control the harmful effects and raise the positive effect of the service.

- Using antivirus software to secure a $P C$.

c) Tell customers about the potential for failure in service if they do not follow instructions.

- Cars factories provide guide books for new cars. 
10.Preliminary Action (Prior Action)

11.Beforehand Cushioning
The primary goal is to provide a Pre-Service.

This principle indicates that a prior action is performed before the service is launched. Preliminary action, or pre-service, can lead to faster and easier services. Preparing all the facilities and utilize the resources associated with the service will add value and improve the quality of the service. Pre-service sometimes requires learning new skills from consumers before they launch it. For instance, a customer booking tickets online before leaving to the theatre.

The primary goal is to mitigate harmful effects.

We should accept the fact that nothing is perfect. This principle is used to prepare for worst-case scenarios. Harmful processes or undesired actions that mitigate the effects, instead of looking to eliminate them. d) Draft an agreement between the service provider and customers.

- A mobile phone warranty is limited to component and does not cover accidents such as water damage.

e) Prepare a support service team.

- Telecommunication companies provide online customer support services.

f) In some cases, the preliminary counteraction involves leaving a seemingly negative effect in place (Fox, 2008).

- Companies increase their service levels before they increase their service prices (Conley, 2009)

g) Principle “\#11: Beforehand cushioning" provides suggestions for contingency plans.

a) Speed up the service by creating appropriate conditions before it is launched.

- Online services that require the customer to enter their information before they can request a service.

b) Get feedback from customers in order to prepare a service according to their needs.

- Data Mining, where the needs and services are studied ahead of time.

c) Single processes or create additional functions before delivering the service.

- Educational CDs come with prepared examples to help learners.

d) If the customer requires the service immediately, the service process should be simplified to improve its efficiency.

- A university may ask new students to fill their information and submit their documents online before they register.

a) Manage service capacity and smooth customer demand by using a set of preventive strategies (Chai et al., 2005).

- Travel agencies offer lower prices during the off season.

b) Have a contingency plan for any problems that may affect the service.

- Backing up data to a server so that no 
12.Equi-Potentiality (Remove Tension)
13.The Other Way Round (Inversion)
The primary goal is to provide the service with minimum energy spends for auxiliary reasons.

This principle is related to changing a service so that it is less expensive or stressful. For example, a tourist vacationing abroad may realized that they have too much luggage and decide to ship some of it to their destination rather than carrying it with them. This prevents stress and potential problems. In terms of providing a service, processes and tasks can be changed to reduce stress by reusing current resources, capitalizing on environmental traits, or restructuring the service.

The primary goal is to think about a service from an opposite viewpoint.

This principle is very important. It encourages a different perspective and finds unique ways of solving a problem. Doing the opposite of what is normal differentiates a service and brings in new customers. Moreover, information is lost.

c) Find a way to reduce the effects of a harmful function.

- An operating system, like Windows, embeds a help feature in case the user faces any problems.

d) Compensate for low reliability in a service by providing supporting services.

- Provide guide books for digital equipment.

e) If necessary, illustrate to customers the risks of using a service.

- Hospitals frequently reduce their responsibility by having patients sign a waiver before undergoing surgery..

f) Shift the risk of failure to a third party.

- Enterprises use insurance companies to cover the costs of disasters including fire, earth quakes and robbery

a) Limit the service conditions to make it more comfortable for the customer.

- A car rental company may allow a customer to return their rental to another branch at a more convenient location.

b) Eliminate the pressure on a service by changing the service offer.

- In universities, instead of offering many classes in a semester, classes are provided during semesters break.

c) Make customers do less to minimum efforts for receiving the service.

- E-banking allows customer to complete their transactions online instead of visiting the bank.

d) Lower service capacity.

- First come first served.

e) Principle “\#9:Preliminary anti-action" provides further information for avoiding problems before they happen.

a) Make the service delivery in an opposite way.

- Hospitals send imbalance to bring a patient.

b) Instead serving customers directly, provide a self-service option.

- E-services allow customers to shop and 
this principle can help a service provider become more competitive by discovering the deficiencies of competing service providers so that those deficiencies can be avoided. The other way around principle also may guid for producing a service in a field that most competitors are not interested in providing.
14.Spheroidality (Curvature )
15.Dynamization
The primary goal is to create a nonlinear process.

This principle can be used as a lens to identify where change is needed in the service process, or where processes can be combined with other process or functions. In particular, linear services can be transformed into iteration. For example, in order to keep up with customers need changes, a service provider conduct an iterative survey or interview customers to get their ideas for developing a new service or redesigning a current one. This principle can also be used to identify if a services that are frequently used by customers. Moreover, the Spheroidality Principle also helps to develop indirect services. For instance, creating a cheerful atmosphere will indirectly create a good impression on a customer.

The primary goal is to allow service processes to change.

Dynamization principle makes services more flexible so that they make payment without the need to go to the store (J. Zhang et al., 2003).

c) Create a service that does the opposite of what others do.

- In some gas stations, consumers pump their own gas from the pump and use a credit card at the gas pump to pay.

d) Add new functions or features that make the service act in an opposite way.

- Pay for customers in some conditions by offering free vouchers after the customer buys a certain amount of product.

e) Increase service capacity instead of decreasing it during a recession (Conley, 2009).

- To attract more students, some language institutes offer an extra remedial course.

f) Allow customers to design the service (Retseptor, 2005).

- Companies conduct surveys, interview, and listen to customer complaints in order to enhance their services.

a) Avoid service obstacles by moving around them instead of fighting through them (Conley, 2009).

- Positive customer feedback helps companies eliminate obstacles that convince new customers to avoid using their services.

b) Add a new indirect value to the service instead of looking for direct value.

- Background elements (temperature, lighting, music, color, furnishings) in a service facility provide indirect value to customer.

c) Make necessary service events, offers, or process occur more frequently.

- Co-creation to enhance a service.

d) Turn linear service into a circular one.

- In some English institutes, they rotate their teachers each term to avoid boring routines.

a) Change the service according to the circumstances.

- Some stores change the price of products or services according to the 
can meet the demands of customers. The need for flexibility could be related to temporary situations (time), environment (location), or a group of people (customization). This principle acts as a lens for viewing possible service changes to make services more movable, flexible, and adaptable in different situations.

16.Partial or Excessive Actions (Slight Less/Slightly More)
17.Another Dimension
The primary goal is to do more or less functions, efforts, tasks, or activities.

In some situations, services cannot achieve their desired results even though they have a reasonable amount of features or functions. Using more or less features or functions in a service process may provide a solution. For example, management meetings may change from monthly to weekly or even every 3 months. This principle can also be used to mitigate negative effects.

The primary goal of this principle is to think about different versions or levels in the service.

This principle encourages thinking about changing the look of a service, season.

b) Increase or decrease service capability based on time or demand.

- Cinemas increase display sections during the weekend.

c) Make the service adapt to the environment.

- Some websites change their language automatically according to the user's profile.

d) Allow a service to move from location to another.

- A community service moves from one place to another to conduct social activities.

e) Allow customers to customize the service according to their needs.

- Students choose different courses each semester.

f) Principle “\#3: Local Quality” provides more customizing ideas.

a) Improve the process of the service by using a little less (or more) push.

- Service regulations can be more flexible so customers can use it without the need to go in many processes.

b) Consider new conditions or a new market for the service and avoid wasting your time or efforts where it is not suitable or demanded.

- Companies open different branches in different locations.

c) Think of ways to make services exceed customer expectations.

- Mall centres sometimes offer child care and entertainment for children to make parents shopping less exhausting (J. Zhang et al., 2003).

d) Find ways to mitigate undesirable service processes as much as possible.

- Some universities focus on increasing the number of postgraduate students and decrease the number of bachelor students so that they can be considered to be research universities.

a) Add a new dimension to the service that will create a new value.

- Mobile applications, such as Windows for mobile is a new dimension that was added to the formal operating system. 
18.Mechanical Vibration (Resonance)

19.Periodic Action how the service is used, how it can be differentiated, or add a new concept for performing the service. For instance, when the results of a particular service are reported, new ways of relating this information to the customer should be considered, such as using figures or charts instead of numbers or data.

The primary goal of this principle is to consider instability.

Services may need to change from being stable to being variable. This principle is used to improve service quality or change company services according to the vagaries market or customer demands. Resonance principle also suggests using other parameters to "stir things up".

The primary goal of this goal is to think of opposite continuity.

This principle refers to changing a service offers, or delivery from continuous to periodic. Periodic actions can be used to increase or decrease a service. In addition, particular occasions or events in the market may require using the principle of periodic actions for a service such as changing the frequency of the action, or perform other actions from time to time. b) Differentiate a service by bringing a new experience to customers.

- $3 D$ cinemas provide a new and exciting experience to the audience

c) Improve service performance by providing different means to access and utilize it.

- Banks authorize customers to manage their financial and transportation online.

d) Consider using different service levels for different types of customers.

- Airlines have different travel class such as economic, business, and first class

a) Increase the frequency of service offers.

- Shops make discount offers frequently.

b) Alter service offers to meet customer expectations.

- Restaurants diversify their menus from one day to another.

c) Make the operation of the service, its capacity, or other offers variable.

- Some telecommunication companies offer discounts for conducting calls during certain hours.

d) Principle “\#15: Dynamization" provides additional suggestions for increasing the efficiency of a service.

a) If a service is available all the time, it may be beneficial to make it available only during certain occasions. In other words, change the service from continuous to periodic.

- Tourism companies include visits to certain islands only in the summer.

b) If the service is already periodic, its frequency can be changed.

- If a travel agency already includes visiting islands only in summer, change the time of the visits to spring.

c) Exploiting decreasing demand for services to perform other functions.

- Universities exploit summer vacation to promote themselves in other countries.

d) Provide special offers only during off-peak times.

- "Some cinemas put on more show sessions in weekends",(J. Zhang et al., 
20. Continuity of Useful Action

21.Skipping (Hurrying)

22.Blessing in Disguise" or "Turn Lemons into Lemonade (Convert Harm Into Benefit)
The primary goal of this principle is to do continuously the useful actions.

This principle refers to making the useful actions in a process work continuously. The process may have idle or ineffective processes that can be removed to increase efficiency. Moreover, this principle attempts to provide many services simultaneously.

The primary goal of this principle is to shorten waiting times.

This principle suggests increasing the speed of delivering services. This principle can be used to skip unnecessary functions that may cause delay. One way to alter the performance speed is by allowing customers to serve themselves. In addition, this principle can improve competitiveness. Removing a long and boring process from a service will add value to the service.

The key purpose of this principle is to convert a harmful process, function, or event into a useful one.

A harm action, function or event could happen any time a service is provided to customers. Usually, the
2003).

e) Refer to Principle “\#1: Segmentation" in order learn more about segmenting a service and to Principle "\#18: Mechanical Vibration" for further information about the frequency of a service.

a) Make services available as long as you can.

- Instead of providing a service for 12 hours, providing it for 24 hours.

b) Make services available more frequently.

- Online booking system allows customers to access the service any time.

c) Eliminating idle or intermittent actions or work to ensure continuity of service.

- Instead of checking emails using PC, software such as Android synchronizes emails with a mobile phone automatically.

d) Exploit useful functions in the service to do other tasks in parallel to achieve continuously useful functions.

- Cinemas provide food and drink to the audiences while they watch the movie.

a) Shorten the waiting time for a service.

- Emergency departments in hospitals shorten the time it takes to see a specialist.

b) Increase the level of automation in the service.

- Auto answer machines.

c) Change the service to reduce customer contact time.

- ATM machines.

d) Accelerating the functions or actions of the service process.

- Use touch and go in Plaza tolls.

e) Principle "\#18: Preliminary Action" provides more information about how to speeding up a service actions.

a) If a harmful action or event is inevitable, increase the harmful action or event in order to provide a new value.

- Increase the cost of water services to 
23.Feedback

24.Intermediary negative effects are associated with the environment, time, place, resources, information, and function of the service. This principle suggests using harmful occurrences as a way to realize benefits. It also recommends exploiting harmful functions in order to determine weakness in a service and take effective actions to reduce harmful effects.

The key purpose of this principle is to use outputs as inputs.

This principle refers to utilizing market indicators or information from the market in order to improve a service. Any output from a service can be used as input to enhance that service. Thus, focusing on customer perceptions provides good feedback for an organization and can direct the organization to add more value to the service.

The key purpose of this principle is to find a temporary element that can be easily removed.

This principle suggests outsourcing a part of a service, or for carrying of non-core function, process or action in existing service to improve its capacity or capabilities. The Principle of Intermediary is not usually related to service processes, but it may be used to insure the stability of a service and keep it work continuously. It also can be used to reduce obstacles or harmful actions.

The key purpose of this principle is to allow the customer to play a role in the delivery of the service.

In order to deliver the service, customers require limited skills so reduce usage.

b) Use resources to convert a harmful event into a useful service.

- Listen to customer complaints to find ways to enhance services.

c) Learn from mistakes to avoid failure in future.

- Experiment by providing a trial service to some customers in order to learn about any weakness.

a) Improve a service by getting feedback from customers and data analysis.

- Data mining

b) Utilize customer behaviors in order to make a service more appealing.

- Some companies use bar coding or checkout scanner technology to collect and analyze customer buying behaviors.

a) Associate core services with temporary related services to enhance delivery.

- Using the delivery service offered by restaurants.

b) Use technology as intermediary to deliver a service.

- The Internet is used by some people as an intermediary to find a spouse.

c) Utilize the environment, people, or other resources as an intermediary.

- Companies use their customers to advertise service offer.

d) Involve others functions as intermediary to reduce harmful actions, other risks, or to improve a service.

- Hire temporary employees during busy seasons.

e) Organizations can outsource non-core functions or process so that they can focus on more valuable functions.

- Using PayPal for payment.

a) Make the service to be utilized by the consumers without interaction with front line employees.

- Using ATM to do various financial transactions. 
they can use the service by themselves. This principle can be used as a cost-saving strategy when the delivery of the service does not require the customers to interact with front line employees. The Self-service Principle also encourages the problem solver to think about how to create new values from operating a current service. For example, increasing the speed of a service will make a good impression on customers and they may introduce the service to others.

\section{Copying}

\section{Cheap}

Short-Living

Objects (Cheap

Disposables)
The key purpose of this principle is to copy things from others

The Copying principle is useful in terms of competition. This principle can be used to imitate another service, but in a less expensive way. Moreover, this principle also suggests applying concepts from other fields. Technically, the Copying Principle suggests replacing an object or process with visual copies. For example, CCTV can be used to provide feedback regarding customer behavior instead of using a survey or customer interviews.

The key purpose of this principle is to replace an expensive object with a cheap object.

This principle encourages the creation of an inexpensive copy that can be used and disposed after period of time. This principle does not mean replacing an object. Instead it refers to adding a cheap, short-lived disposables function or process to a core service. b) Determine which part of the service is most affected by delivery speed. Then find a way to convert that process to a self-service method.

- Online payments can be used to speed sale transactions.

c) Facilitate a service by providing automatic support functions or processes for the customer.

- In supermarkets, customer can use scanners to check the prices of some goods.

d) Increase customer participation in the delivery of the service.

- Consumers pump their own gas and use a credit card at the gas pump to pay.

a) Replace a high cost or fragile service with low-cost or durable copies.

- Use electronic media, such as CDs to learn instead of attending a class.

b) Make different copies of a service and give the customer a chance to choose one that is convenient.

- Download websites give options such as free limited speed downloads or premium accesses for fast download.

c) Apply other business, mathematical, or computer models or simulations to a current service.

- Automatic vending machine can perform different services such as returning library books or posting letters. (Chai et al., 2005).

a) Give a simple copy of the service to the customer in order to try it before they make their purchase.

- Trial software.

b) Add a new function, process, or part to the core service that can be easily disposed after the service has been delivered.

- Restaurants hire extra temporary employees during peak seasons.

c) Perform some process or functions of the service ahead of time in order to reduce costs, facilitate the delivery of the service, or increase convenience.

- Universities provide guide books to students before they register. 
28.Mechanics

Substitution

(Another Sense)

29.Pneumatics and Hydraulics (Intangibility)

30.Flexible Shells and Thin Films (Thin and Flexible)
The key purpose of this principle is to use the senses.

This principle substitutes mechanical means with sensory means. This principle provides several options to make changes in your service using sensory means (visual/ optical, audio/sound, smell, touch, or test).

The key purpose of this principle is to focus on customer mindsets.

Customers sometimes require different values in order to convince them to purchase a product or service. This principle suggests evaluating and focusing on intangible issues, such as quality.

The key purpose of this principle is to isolate harmful issues by using thin barrier or using a flexible structure.

This principle is concerned with isolating functions, process, activities, or problems in order to improve service quality, reduce costs, and increase reliability.
31.Porous materials (Holes)
The key purpose of this principle is to create holes in a system to improve a service preforming.

This principle refers to two steps. The first step is to open channels to obtain useful information for creating new ideas for a service. The second step is a) Use sense means such as visual/ optical, temperature, lighting, music, olfactory, or test or improve value.

- “Supermarkets pump bakery odours around the store to help advertise bread products",(Mann, 2007)

a) Advertise a service differently in order to generate value.

- An organization may support social activities in the community to indirectly advertise their product.

b) Focus on the quality of a service to entice customers.

- a brand associated with a service can be a guarantee of service quality (Chai et al., 2005)

a) Flexibility can improve the interaction between customers, employees, and management.

- Some companies use customer service employees as a 'flexible shell' to reduce obstacles between management and customers.

b) Use a thin barrier to improve service quality

- E-banking sends an approval code (thin barrier) to a customer's mobile as part of a security procedure when the customer wants to transfer money from one account to another.

c) Isolate a customer from harmful environments or interactions using a flexible structure.

- Internet coffee houses isolate smokers from non-smokers

d) Isolate a harmful function in a service from its environment using flexible procedures.

- Some car maintenance shops offer a rental car to their customers if maintenance will take some time to complete.

a) Open channels (hole) to listen to consumers in order to enhance the service. Principle "\# 23: feedback" provides further suggestion for listening to customers.

- Live chat function on websites.

b) Use technology to connect with 
to improve service interactions through enhance service proactivity, function, or internal or external communication. In addition, porous materials can be used as a lens to see deficiencies and find the time, resources, space or functions that can fill these voids with useful activities or functions.

32. Color Changes (Change the Color)

33.Homogeneity
The main task of this principle is to focus on customer comfort or the reliability of a service.

This principle can be used to address physical characteristics such as the colors in the external environment to satisfy a customer, or intangible aspects, such as offering different options for delivering the service that add value to customer. Color change can also be related to transparency and trust.

The main goal of this principle is to focus on the consistency of a service.

Homogeneity can be used to looking similar features and functions in a service that can be grouped or work with the culture of customers in order to satisfy their needs. customers and remotely a service.

- Patients can get online assistance from their doctors.

c) Eliminate any obstacles to the delivery of service by creating holes in the service in order to facilitate service consumption.

- An express counter (holes) in supermarkets expedites the sale process.

d) Utilize company resources to open channels to reach and receive the service effectively.

- Some universities allow their students to access university resources such as the library, or laboratories any time by using smart cards.

e) Make space in service operations to allow other tasks or services to be performed.

- While patients wait to see a doctor in the clinic, they can use the clinic library to read books, newspaper, or watch $T V$.

a) Make the environment around the service enjoyable.

- Malls provide different activities with different decorations to cheer their visitors.

b) Provide the same service with different options (color change) according to customer requests.

- Banks provide different levels of service according to what type of accounts a customer has.

c) Encourage the customer trust a service.

- Some restaurants provide a view into the kitchen (J. Zhang et al., 2003)

a) Segment people and develop services that are consistent with their needs. Principle “\#1:Segmentation” for a further illustration of segmentation.

- Schools employee experts who have experience teaching students according to their ages.

b) Make a service work with other similar services.

- Some parking lots provide secure gates to keep a car safe and provide a car washing service while the car is parked.

c) Package similar services together. 
34.Discarding and Recovering (Rejecting and Regenerating Parts)

\section{Parameter Changes}

(Transformation of Properties)
The key purpose of this principle is to remove and reuse elements directly after they have fulfilled their functions.

This principle has two methods. The first method is to remove some functions or resources from a service after completing a task. The second method is to reuse some functions or resources after fulfilling the assistance job. Think about an unnecessary aspect of a service that can disappear after its use fulfilling (Fox, 2008)

The key purpose of this principle is to focus on the properties of a service.

This principle is about changing the properties of a service such as service flexibility, consistency, ship, quality, etc. Think in resources are available within the service and how those resources can be utilized for changing the service operation, and enhancing customers prospective, experience, or value.
Principle \#5 “Merging” to learn more about merging services.

- Gyms provide nutritional consulting as part of their health programs to give additional value to their customers.

d) Make a service suitable for a specific culture.

- Some Hotels in Japan provide a copy of the holy Quran (Muslims holy book) and prayer rugs for any Muslim customers who stay in their hotels.

a) Group a permanent service with a temporary service and then separate them after the service is performed. See principle \#27 "Cheap short-living objects" for further information on cheap disposable services.

- E-banks sometimes give a customer a tag number to be used during a period of time for any transportation or any mobile payments.

b) Reuse information from a service to enhance the service.

- Some companies use bar coding or checkout scanner technology to collect and analyze customer buying behaviors.

c) Change a how a service operates for a period of time.

- Manufacturers of soft drinks may launch an awareness campaign to educate people about harmful effects of metal cans or plastic on the environment while providing collection points for these cans for recycling.

a) Change how the physical service is delivered.

- Virtual shopping (e.g. ebuy.com).

b) Change the concentration or consistency of a service.

- Telecommunication companies provide different services to businesses.

c) Change the flexibility of a service and customize services according to customer needs.

- Some restaurants provide open buffets to allow their customers to customize their meals according to their needs.

d) Focus on adding value to the service environment.

- Coffee shops add value by playing mood music in the background and displaying 
paintings.

36.Phase Transitions (Phenomenon Utilization)

37. Thermal

Expansion (relative change)

38.Strong Oxidants (Enriched Atmosphere)

39.Inert Atmosphere (Calm
The key purpose of this principle is to exploit an existing phenomenon.

Any changes in the environment, culture, occasion, or events could be utilized to create new services or add value to a current service. This principle may also use to think on the advantage from economy phenomena. For example, enter to market when others shift out.

The key purpose of this principle is to response to changes.

This principle refers to the expansion and contraction of the service market. It also means arranging different parts of a service to work differently according to fluctuating customer demands.

The key purpose of this principle is to enrich a service with different capabilities or activities.

This principle refers to adding stimulation to a service and introduces elements that accelerate the service process.

The key purpose of this principle is to reduce something in the service. a) Exploit the phenomena of other services to enhance or produce new services.

- Data centres are a good example of exploiting the phenomena of increasing data to sell storage.

b) Exploit the environment, an occasion or event to produce new services or change how a service is delivered.

- Offer light clothing in the summer, and heavy clothing in the winter.

c) If a customer plans to use a service on a particular occasion, prepare a service that accommodates their demands.

- Create new programs in a mall for New Years.

a) Expand or contract the service capacity or location.

- Restaurants hire temporary staff to meet peak demand.

b) Exploit service contractions to expand service capacity in another area.

- Domino Pizza depends more on its delivery services than it does on its restaurants.

c) If another competing service is similar, target new markets or customers.

- Some telecommunication companies offer high speed Internet with better capacity instead of offering low long distance costs.

a) Increase customer participation in the delivery of a service.

- Herbalife uses its customers as independent distributers and share revenue with them in order to encourage their sales.

b) Keep using stimulation to differentiate a service.

- Prize draws for cars or money in malls.

c) Enrich a service with other activities, or features.

- Students have practical classes to apply what they have learned.

a) Eliminate stimulates things.

- Increase payments for the service. For 
Atmosphere) This principle is about reducing risk while operating a service. The environment that the service operates in, the way a service interacts with customers, and the easiest and cheapest way to improve the delivery of the service must be considered. The Calm Atmosphere can be also related to remove any elements that have been used for stimulating a service

The key purpose of this principle is to change homogeneous parts.

This principle opposite of principle “\#33: Homogeneity”. It is about mixes non-homogenous service to increase service value or make it available for different types of people. example, in order to balance Internet bandwidth between users, websites charge customers more for increased internet speeds.

b) Reduce harmful interactions in the service environment.

- Amusement parks increase ticket prices to avoid overcrowding during the weekend.

c) Make a service more convenient and quite for customers.

- Create quiet areas in the work environment (Mann, 2007)

d) Reduce customer concerns regarding any risks they may expose to from a service.

- Online financial transactions reduce customers concern regarding their private information. Customers serve themselves without direct interaction with bank stuff.

a) Combine multiple types of services from different areas.

- Cable companies create diversity by offering different channels packages. (e.g., movies, educational, cartoons, news, etc.).

b) Use a service for different purposes.

- Facebook can be used for social or business purposes.

c) Add tangible elements to intangible elements in a service.

- Hotels provide complimentary toiletry items with the hotel name prominently displayed (J. Zhang et al., 2003).

\section{Results}

During the process of interpretation, the authors noted several issues regarding TRIZ principles. The first issue was that the examples used to illustrate each principle were pulled from several different areas and that several principles had attributes that were similar (Cong \& Tong, 2008; Gazem \& Rahman, 2013b; Rantanen \& Domb, 2002). As a result, some interpretations suggest that the problem solver look at other principles for additional information. Linked principles create different views that could help the problem solver create innovative solutions (Rantanen \& Domb, 2002). Another issue noted by the authors was that the opportunities to use available technologies with a solution. Solutions offered by information and communication technologies (ICT) can help generate inventive solutions to problems and provide better customer service (Ashrafi \& Murtaza, 2008). Therefore, the authors referred to ICTs in some situations. Finally, we found that some researchers used different terms for some inventive principles. For instance, Principle "\#13:The Other Way Round" has also been called "Do it in Reverse" by (Altshuller et al., 2005) and Principle "\#28:Mechanics Substitution" has also bee referred to "Another Sense" by (Mann, 2007). Additionally, Principle “\#37:Thermal Expansion" has also been called "Strategic Expansion" (Zhang et al., 2003). In this study, the original names for the principles were used with the alternative terms as well. 


\section{Discussion and Case Study}

This interpretation of the 40 IPs for the service sector provides new ways to apply TRIZ principles. However, it is difficulty for problem solvers to manage and remember all the principles (Mann, 2002). Therefore, in order to use the principles effectively, a method for grouping the principles can be used so that the problem solver will not need to go through all principles to generate a solution. Fortunately, a previous study conducted by Gazem and Rahman (2013a) can be used in addition to the interpretations offered in this study to effectively use TRIZ principles. In order to prove the feasibility of using interpretations with grouping methods, we conducted a case study.

The case study involved a travel agency in Malaysia named "Almohit Travel \& Tours Company". The company found that it had inadequate cars during the tourism season and they were considering purchasing more cars to meet the demands of their customers. However, the cars would not be used after the end of the tourism season and those cars would be an encumbrance. In addition, the company would not be able to buy many cars because it is very costly for this small firm to purchase the cars they need.

After this problem was analysed, the contradiction was "the company needs more cars in order to fulfil customers demand during the tourist season time, but the company does not need more cars during non-peak seasons". The company needed to prepare procedures to deal with any possible issues that might arise. Gazem and Rahman (2013a) grouped the 40 IPs according to type to redesign their service. The best approach for solving this problem was to redesign this service using a "per-services approach". Through reviewing the possible principles grouped with that approach, Principle "\#9: Preliminary anti-action" was selected to solve this problem. One of this principle hints suggests "Before negative or harmful effects occur they should be eliminated, prevented or reduced". That led to finding a way to reduce the demand for cars so the company would not have to increase the number of cars in its fleet.

One of the suggestions provided to the company was to allow customers to reserve a car from the website before they come to Malaysia. When the company did not have a car available for a particular customer, the company could ask customers to look at the company car schedule on its website and indicate the period of time that they would need the car. This would help the company arrange and assign its cars for that particular time. In the same time if the cars not free at that time, company would ask its customers to rearrange their time for coming according to the company suggestion and available of the company's cars.

Another principle that may have solved this problem was Principle "\#10:Preliminary Action (Prior Action)". One of this principle hints suggests that the travel agency could "single processes or create additional functions before delivering the service". This guides the problem solver to think about finding a way to provide the required cars before the tourist season begins. One suggestion provided to the company was to make an agreement with cars rental companies and the travel agency would earn a commission. This commission could be discounted from the total cost of the offer package. Thus, the company could reduce the indirect cost of renting a car.

\section{Conclusion}

The unique thing about TRIZ is that it is a theory of problem solution with a knowledge database. This theory provides opportunities for non-technical sectors, especially for service sector to improve their systematic innovation approaches. Using the 40 inventive principles can help designers or problem solvers find effective solutions to service contradiction problems. Examples from different studies helped the authors understand and explain these principles. The method and the structure used to interpret the 40 IPs adapted TRIZ for use in the service sector, to add value to design and redesign services, and to solve service problems. This study demonstrated how designers or problem solvers can understand the meaning of TRIZ principles, directed them to variant hints for best utilizing principles, and included different examples with hints that may add value to their experience and knowledge. This paper also indicated to an opportunity of involving ICT solutions with interpretations. The case study confirmed the usefulness of applying TRIZ principles and emphasized the feasibility of using the interpretations the 40 IPs.

Fully understanding the 40 IPs will make it easier to predict and generate solutions since the designer or problem solvers will know how the principles can be used. Moreover, it will provide a good knowledge database resource. In addition, the interpretation of these principles for service related contexts would encourage more researchers to conduct studies regarding the use of TRIZ in B2C and other business operations.

The work was done by Genrich Altshuller and his colleagues for developing sub-principles using technical patents is needed to be done in service as well. Usually, such work can provide more hints that depend on 
resources found in a literature review. On the other hand, the descriptions and hints offered by this study require further testing in different real life service related situations to create a knowledge database especially for the service sector. This knowledge could then be used to refine the descriptions of the principles and hints suggestions. Therefore, future works should use more case studies and involve more ICT solutions to provide more hints.

\section{Acknowledgements}

I would like to thank Dr. Murad Rassam and Dr. Faisal Alsamet for their efforts in proofreading and giving high value comments in order to enhance this paper outcome.

\section{References}

Altshuller, G., Shulyak, L., \& Rodman, S. (2005). 40 Principles Extended Edition: TRIZ Keys to Technical Innovation (1st ed.). Worcester, United States: Technical Innovation Center, INC.

Ashrafi, R., \& Murtaza, M. (2008). Use and impact of ICT on SMEs in Oman. The Electronic Information Systems Evaluations, 11(3), 125-138.

Berry, L., \& Lampo, S. K. (2000). Teaching an Old Service New Tricks. Journal of Service Research, 2(3), 265-275. http://dx.doi.org/10.1177/109467050023004

Chai, K. H., Zhang, J., \& Tan, K. -C. (2005). A TRIZ-Based Method for New Service Design. Journal of Service Research, 8(1), 48-66. http://dx.doi.org/10.1177/1094670505276683

Cong, H., \& Tong, L. H. (2008). Grouping of TRIZ Inventive Principles to facilitate automatic patent classification. Expert Systems with Applications, 34(1), 788-795. http://dx.doi.org/10.1016/j.eswa.2006. 10.015

Conley, D. W. (2009). 40 Inventive Principles with Business Examples. Retrieved from http://www.innomationllc.com/Files/40 Inventive Principles_Business_InnomationLLC_Rev2.pdf

Dourson, S. (2004). The 40 Inventive Principles of TRIZ Applied to Finance. The TRIZ Journal, October.

Fox, M. (2008). da Vinci and the 40 Answers (1st ed.). Austin, Texas: Wizard Academy Press.

Gazem, N. A. J., \& Rahman, A. A. (2013a). TRIZ Principles in Redesign Service Approaches. Advances in information Sciences and Service Sciences, 5(11), 273-282. http://dx.doi.org/10.4156/jcit.vol8.issue11.59

Gazem, N. A. J., \& Rahman, A. A. (2013b). TRIZ Principles Similarity in Text and Meaning: Elaborating Grouping in Redesign Service Approaches. Journal of Information Systems Research And Innovation, 2(February).

Gazem, N. A. J., \& Rahman, A. A. (2013c). Promoting the Systematic Innovation Process in Small and Medium Enterprises. Journal of Convergence Information Technology, 8(11), 528-535.

Gazem, N. A. J., \& Rahman, A. B. A. (2012). Redesign Services using Inventive Principles: A Case Study. Journal of Information Service Systems Innovation, 2(December), 126-132.

Hartman, D. E., \& Lindgren, J. H. (1993). Consumer evaluations of goods and services: Implications for services marketing. Journal of Services Marketing, 7(2), 4-15. http://dx.doi.org/10.1108/08876049310038364

Hsia, T. -C., \& Pu, L. -B. (2013). Using TRIZ to Improve Maintenance and Repair Services at Jung-xian Auto Repair. Advances in information Sciences and Service Sciences, 5(9), 409-419. http://dx.doi.org/10.4156/aiss.vol5.issue9.49

Kim, S., \& Park, Y. (2012). A TRIZ-based Approach to Generation of Service-supporting Product Concepts. World Academy of Science, Engineering and Technology, 62(111), 574-574.

Kuo, D. C., Chi, C., \& Yeh, H. (2013). A Proposed Methodology and its Implications for Industrial-oriented Service Innovation. International Journal of Advancements in Computing Technology, 5(4), 899-906. http://dx.doi.org/10.4156/ijact.vol5.issue4.108

Lin, C.-S., \& Su, C.-T. (2007). An Innovative Way to Create New Services: Applying the TRIZ Methodology. Journal of the Chinese Institute of Industrial Engineers, 24(2), 142-152. http://dx.doi.org/10.1080/ 10170660709509029

Mann, D. (2002). Evolving the Inventive Principles. The TRIZ Journal.

Mann, D. (2007). Hands on Systematic Innovation: For Business and Management. UK: Edward Gaskell Publishers. 
Mann, D., \& Domb, E. (1999). 40 Inventive (Business) Principles with Examples. The TRIZ Journal, September.

Rantanen, K., \& Domb, E. (2002). Simplified TRIZ: New Problem Solving Applications for Engineers and Manufacturing. Professionals: Auerbach Publications. http://dx.doi.org/10.1201/9781420000320

Retseptor, G. (2005). 40 Inventive Principles in Marketing, Sales and Advertising. TRIZ Journal, April.

Wolak, R., Kalafatis, S., \& Harris, P. (1998). An Investigation Into Four Characteristics of Services. Journal of Empirical Generalisations in Marketing Science, 3, 22-43.

Zhang, J., Chai, K. -H., \& Tan, K. -C. (2003). 40 Inventive Principles with Applications in Service Operations Management. The TRIZ Journal, December.

Zhang, Q. (2013). Research on Customer Satisfaction in B2C E-Commerce Market. 209, 283-291.

\section{Copyrights}

Copyright for this article is retained by the author(s), with first publication rights granted to the journal.

This is an open-access article distributed under the terms and conditions of the Creative Commons Attribution license (http://creativecommons.org/licenses/by/3.0/). 